\title{
Differential trends in mortality from AIDS in men and women in Brazil (1984-1995)
}

\section{Catherine M. Lowndes ${ }^{a, *}$, Francisco I. Bastos ${ }^{b}$, Karen M. Giffinc, Ana C.G. Vaz dos Reis ${ }^{d}$, Eleonora d'Orsi ${ }^{\mathrm{d}}$ and Michel Alary ${ }^{\mathrm{e}}$}

\begin{abstract}
Objective: To analyse trends in AIDS mortality in men and women in Brazil, for the period 1984-1995.

Design and methods: National statistics on yearly numbers of reported deaths by cause, in conjunction with census population counts and inter-censory estimates, were used to calculate age- and sex-specific AIDS mortality rates for Brazil as a whole and for São Paulo and Rio de Janeiro, the two largest cities in Brazil, and those most affected by the AIDS epidemic to date.

Results: Numbers of reported deaths from AIDS have increased yearly in Brazil since 1984, to approximately 15000 in 1995 . The data suggest that after a very dramatic rise in mortality rates, the epidemic may have started to slow even before the introduction of freely available highly-active anti-retroviral therapy, although unequally in terms of both geographical and sex distributions. Women also tended to die at relatively younger ages than men in all areas studied, and by 1995 the impact of AIDS on overall mortality was practically the same for men and women aged 25-34 years ( $21 \%$ in São Paulo).

Conclusions: Trends in mortality from AIDS in Brazil reflect both the geographical expansion of the epidemic outwards from its original epicentres, and the fact that women are becoming increasingly affected by the AIDS epidemic.
\end{abstract}

(c) 2000 Lippincott Williams \& Wilkins

AIDS 2000, 14:1269-1273

Keywords: AIDS, mortality, men, women, Brazil, Latin America

From the ${ }^{a}$ Department of Epidemiology, National School of Public Health (ENSP), Oswaldo Cruz Foundation (FIOCRUZ), the ${ }^{\mathrm{b}}$ Department of Health Information, FIOCRUZ, the ${ }^{\mathrm{C}}$ Department of Social Sciences and the ${ }^{\mathrm{d}}$ Gender and Health Nucleus, ENSP, FIOCRUZ, Rio de Janeiro, Brazil and the e Epidemiology Research Group, Department of Social and Preventive Medicine, Laval University, Québec, Canada. *C.M.L. is now with the Epidemiology Research Group, Laval University, Québec, Canada. Sponsorship: Financial support for this study was provided by the Ford Foundation (Grant no. 950-0546), the Brazilian National Research Council (CNPq) and the Oswaldo Cruz Foundation (FIOCRUZ). C.M.L. was supported in part by a visiting scientist award from the Brazilian National Research Council (CNPq). M.A. is the recipient of a research scholarship from the Québec Health Research Council [FRSQ, Fonds de recherche en santê de Québec (Grant no. 970097)]. Partial financial support for F.I.B. was provided by a joint exchange scholarship from the Medical Research Council of Canada and CNPq/ Brazil.

Note: The Oswaldo Cruz Foundation, Rio de Janeiro, Brazil is a UNAIDS Collaborative Centre.

Correspondence to Dr Catherine M. Lowndes, Epidemiology Research Group, Hôpital du Saint-Sacrement du CHA, 1050 chemin Ste-Foy, Québec, Qc, G1S 4L8, Canada.

Email: clowndes@gre.ulaval.ca 


\section{Introduction}

In Brazil, with a population of 165 million people, over 170000 cases of AIDS were officially reported to the National AIDS Case Registry (SINAN/AIDS) by August of 1999 [1].

The AIDS epidemic in Brazil can be described according to three phases of evolution $[2,3]$. The initial phase was characterized principally by infection in haemophiliacs and men who have sex with men. The second phase involved increases in cases due to transmission through injection drug use and dissemination among heterosexuals (particularly female partners of male injection drug users and male bisexuals), as well as the geographical spread to urban areas of all states in Brazil [4]. The third and current phase is characterized by an increasing tendency towards dissemination of HIV/ AIDS among heterosexuals, principally women, and further geographical expansion to smaller municipalities [2].

The vast majority of AIDS cases $(\sim 70 \%)$ continue to be notified from the wealthiest, industrialized, southeast region of the country [3], with concentration in São Paulo and Rio de Janeiro states around 50 and $14 \%$ respectively, of all reported cases (cumulative AIDS incidence rates for cases reported to February 1998 are 211.7 and 140.8 per 100000 population, respectively).

The objective of the present study was to explore characteristics of, and trends in, mortality from AIDS in men and women in Brazil, at national and regional levels, using data from the National Mortality Information System, in order to gain additional understanding of the dynamics of the AIDS epidemic in Brazil.

\section{Materials and methods}

Information on numbers of deaths was obtained from the Brazilian Mortality Information System (SIM: DATASUS, Ministry of Health, Brazil), where causes of death are registered according to the Ninth Revision of the International Classification of Diseases (ICD-9: [5]). Numbers of deaths with AIDS (code:279.1) and total number of deaths were tabulated according to year of death, age, sex and municipality of residence, and transferred to Excel spreadsheets for calculations of mortality rates and production of graphs.

For calculation of sex- and age-specific mortality rates for Brazil, São Paulo and Rio de Janeiro, yearly resident population sizes, from national census data and inter-censory projections, using geometric interpolation
[6], were obtained from the Brazilian Institute of Geography and Statistics.

AIDS mortality rates were analysed for Brazil as a whole and for the capital cities of the two states most affected by the AIDS epidemic, São Paulo and Rio de Janeiro. Analyses concentrate on men and women of reproductive age (15-49 years), and focus particularly on the 25-34 year age group, where AIDS has had the greatest impact on overall mortality.

To examine the impact of AIDS on mortality at different ages, 1994 rates were analysed for men and women by 5 -year age group. For comparison of numbers of reported AIDS cases and deaths, the age groups 13 years and older and $13-49$ years were used, as these are the groupings used in the presentation of national AIDS case data $[1,3]$.

The present analysis confines itself to data pertaining to the years 1984-1995, for which consolidated national mortality data are currently available; in addition, this represents the period before highly-active anti-retroviral therapy (HAART) was made universally available in Brazil, at the end of 1996 [7].

\section{Results}

A total of 68270 deaths from AIDS were registered in the SIM to the end of 1995 (first death in 1984), with 66498 of these deaths occurring in men and women aged 13 years and older, and 14676 deaths reported for this age group in 1995 alone. For the latter age group, the proportion of AIDS deaths in women increased from $3.4 \%$ (5 of 147), in 1985, to $22.6 \%$ (3319 of $14676)$, in 1995. Reflecting this, the ratio of deaths from AIDS in adolescent/adult males and females decreased from $28: 1$ in 1985 to approximately $3: 1$ in 1995. In Brazil, $42 \%$ of all AIDS deaths to date have been concentrated in the age range 25-34 years, and $80 \%$ in the age range $20-44$ years. For the same period (to end 1995), 95847 cases of AIDS in adolescents/ adults were reported to the SINAN/AIDS, of which 56286 (59\% of reported cases) were reported to have died [3].

Figure 1 shows mortality rates from AIDS for men and women aged 15-49 and 25-34 years, for the period 1984-1995, for Brazil, São Paulo and Rio de Janeiro. Substantial and sustained yearly increases in AIDS mortality rates occurred during this period. Peak mortality rates in men aged 25-34 years in both São Paulo and Rio de Janeiro were seen in 1994 (123 and 88 per 100000 , respectively), with a small decrease in rates (to 113 and 80 per 100,000, respectively) seen in 1995. 
(a) Men

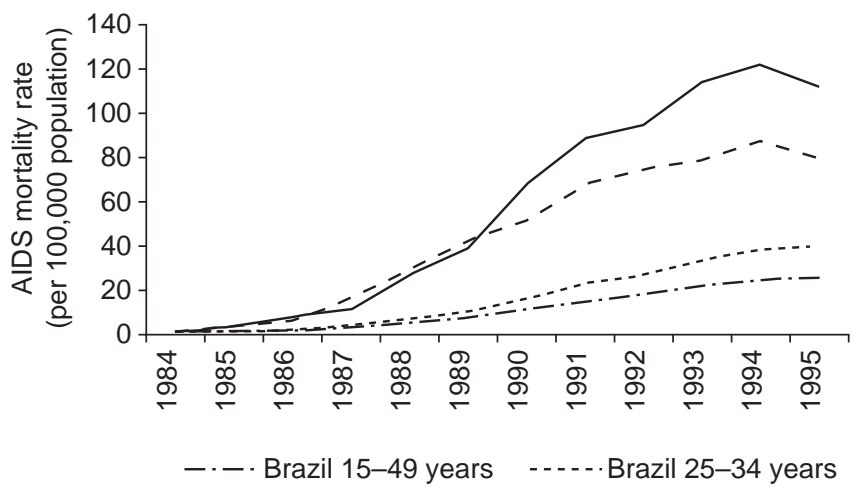

(b) Women

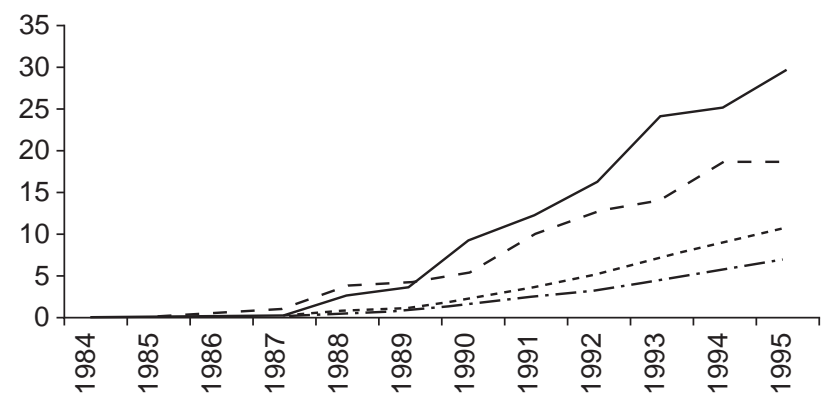

Fig. 1. Yearly AIDS mortality rates per 100000 population, from 1984 to 1995, in men and women aged 25-34 and 15-49 years in Brazil, São Paulo and Rio de Janeiro. [Source: Ministry of Health (SIM: DATASUS) and Institute of Geography and Statistics (FIBGE), Brazil.]

Extremely high rates of yearly increase in AIDS mortality occurred during the early years of the epidemic (for Brazil as a whole, between 1987 and 1989, the increase was $223 \%$ for men and $485 \%$ for women aged 25-34 years), while from the beginning of the 1990s the rate of increase has slowed in all geographical areas analysed.

This slowing is particularly evident in men aged $25-34$ years in Rio and São Paulo, where from 1993 to 1995 the rates remained fairly stable $(-1.4 \%$ for São Paulo and $1 \%$ for Rio). In contrast, in women during the same period, AIDS mortality rates in Brazil as a whole (48\%), and in Rio (34\%) and São Paulo (23\%), have continued to increase significantly, as have rates for men in Brazil as a whole (18\%).

From 1985 to 1995, the proportion of all deaths due to AIDS in men aged 25-34 years increased from 0.2 to $11.3 \%$ in Brazil, from 0.8 to $20.9 \%$ in São Paulo, and from 0.8 to $16.1 \%$ in Rio de Janeiro. For women, before 1990, AIDS accounted for a negligible proportion of total deaths. However, between 1990 and 1995, the proportional mortality from AIDS in women in the 25-34 year age group increased from 2.2 to $9.9 \%$ in Brazil, 8.1 to $21.1 \%$ in São Paulo, and 4.0 to $14 \%$ in Rio. Thus, by 1995, AIDS accounted for fairly similar proportions of all deaths in men and women in this age group in Brazil.

Figure 2 shows 1994 mortality rates from AIDS in adolescent/adult men and women in Rio de Janeiro and São Paulo municipalities, by 5 -year age group. A total of 1123 deaths from AIDS in men and 281 in women aged 15 years and older occurred in Rio in 1994; in São Paulo, 2369 AIDS deaths in men and 543 in women were reported. AIDS mortality rates peaked at 30-34 years in men and 25-29 years in women in São Paulo; in contrast, the highest rates in Rio occurred in the 35-39 years age group in both men and

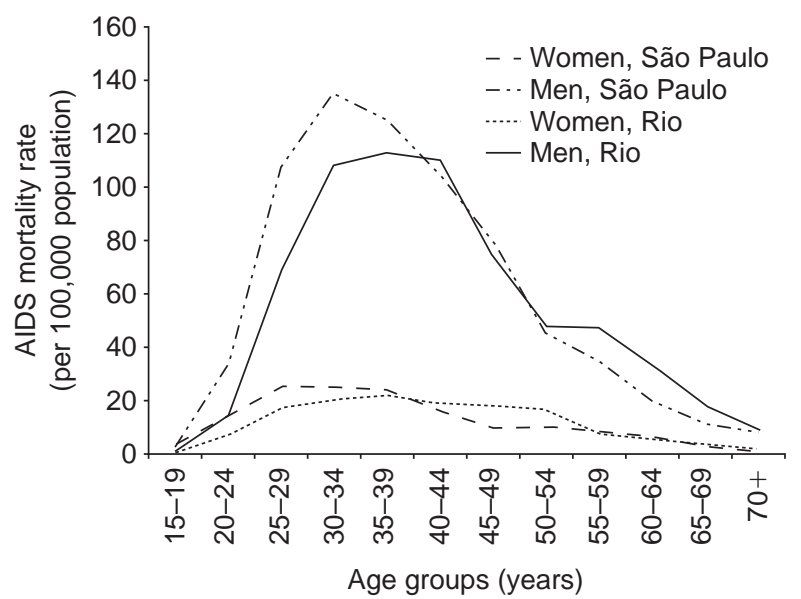

Fig. 2. AIDS mortality rates (per 100000 population) in men and women per 5-year age group, São Paulo and Rio de Janeiro, 1994. [Source: Ministry of Health (SIM: DATASUS) and Institute of Geography and Statistics (FIBGE), Brazil.]

women. AIDS mortality rates for 1994 were higher at younger ages for men in São Paulo than Rio de Janeiro; and this pattern was also seen in women. Conversely, for both men and women, rates were higher at older ages in Rio de Janeiro than São Paulo.

\section{Discussion}

The number of deaths from AIDS in Brazil to end 1995, registered in the SIM, is $21.3 \%$ higher than the number reported to the SINAN/AIDS (68 270 versus 56 286) [3]. Under-representation of numbers of AIDS deaths in the SINAN/AIDS may be partly due to lack of status updates on previously-reported AIDS cases. In addition, studies in Rio and São Paulo indicate that a significant proportion of AIDS cases in Brazil are 
detected only at death $[8,9]$. Cases identified at death may not always be reported to SINAN/AIDS. Biases in AIDS case reporting may also occur due to factors such as lack of recognition of the likelihood of disease occurrence in women [10] and access to therapy $[11,12]$. Overall, these data indicate that data from the SIM provide a more complete picture of the burden of AIDS on mortality in Brazil than data from the SINAN/AIDS.

Although AIDS mortality rates appear to be stabilizing and even decreasing in men aged 25-34 years in Rio and São Paulo, the rates continue to increase in women in this age group. AIDS mortality rates are also increasing at a faster rate in women than in men in Brazil as a whole. The impact of AIDS on overall mortality in 1995 was similar for men and women, accounting for over one-fifth of all deaths in the age group 25-34 in São Paulo, about 15\% in Rio and about 10\% in Brazil as a whole.

Differential access to care for HIV/AIDS may partially account for the differential trends in mortality rates in men and women $[13,14]$. Under-recognition of AIDS as an illness in women, particularly during the early stages of the epidemic, has been well documented in countries such as the USA [10]. Although heterosexual transmission is the dominant mode of HIV infection in women in Brazil, available data suggest that, as in many other countries, many infected women are not in 'high-risk' groups, but rather are monogamous women in ongoing relationships $[15,16]$ who may be aware of their risk of exposure at the same time as being unable to protect themselves from infection [17].

In the analyses of 1994 mortality rates by age group, this excess mortality from AIDS at younger ages in women in comparison with men is evident. These findings probably reflect sexual mixing patterns, namely the tendency for women to have older male sexual partners, as seen in industrialized countries, where median age at death from AIDS is 3 to 9 years greater in men than in women [18].

Although rates of AIDS mortality in Brazil are lower in women than in men, the difference in AIDS mortality rates between men and women tends to be substantially greater in most developed countries than in Brazil. This can be most clearly seen in the male : female ratio of number of deaths, which is $5: 1$ in Spain and Italy, $9: 1$ in the USA, $10: 1$ in Germany and $15: 1$ in Canada [18]. Thus, the relative impact of AIDS on mortality in women in Brazil, with a male: female ratio of close to $3: 1$ in 1995 , is considerably greater than in most developed countries. In terms of its impact on women, therefore, Brazil is situated between industrialized countries and countries in sub-Saharan Africa, where $90-95 \%$ of cases are due to heterosexual transmission, and sex ratios of reported AIDS cases tend to be around $1: 1[19]$.

Finally, it should be noted that the apparent slowing of the velocity of the epidemic in Brazil, as observed in the mortality data presented here, and in AIDS case data, occurred before the universal introduction of HAART in late 1996 in Brazil. In this context, future effective monitoring of trends in the HIV/AIDS epidemic in Brazil will require extensive surveillance of numbers of new HIV infections, as both reported AIDS cases and deaths become progressively less indicative of rates of occurrence of new HIV infections. Of particular concern is the extent to which the increasing heterosexualization, 'feminization' [15] and geographical expansion of the AIDS epidemic [2] reflect penetration into the general heterosexual population.

\section{Acknowledgements}

The authors thank Joaquim G. Valente, Katia R. Valente Lemos, Benoît Mâsse and Caty Blanchette for helpful discussions on data analysis and interpretation; Franklin Monteiro da Silva and Fabíola Araujo Cordeiro for technical support, and Céline Valin for assistance in manuscript preparation.

\section{References}

1. Ministry of Health, Brazil - National STD/AIDS Programme Boletim Epidemiológico AIDS [AIDS Epidemiological Bulletin] November 1998, XI:issue 4.

2. Szwarcwald CL, Bastos FI, Castilho EA. The dynamic of the AIDS epidemic in Brazil: a space-time analysis in the period 19871995. Braz J Inf Dis 1998, 2:175-186.

3. Ministry of Health, Brazil - National STD/AIDS Programme. Boletim Epidemiológico AIDS [AIDS Epidemiological Bulletin] February 1998, XI:issue1.

4. Barcellos C, Bastos FI. Redes sociais e difusão da AIDS no Brasil [Social networks and the diffusion of AIDS in Brazil]. Bol Oficina Sanit Panam 1996, 121:11-24.

5. World Health Organization. International Classification of Diseases. Manual of the International Statistical Classification of Diseases, Injuries, and Causes of Death. Ninth Revision. Geneva: World Health Organization; 1977.

6. Beltrão $\mathrm{KI}$, Pereira $\mathrm{MC}$. Estimativas por interpolação das populações residentes no Brasil, nas grandes regiões e nos municípios das capitais nas regiões metropolitanas - período 1980/1991. In Os Muitos Brasis: Saúde e População na década de 80. São Paulo: Hucitec/Abrasco; 1995:338-345.

7. UNAIDS. NGO perspectives on access to HIV-related drugs in 13 Latin American and Caribbean countries. Geneva: UNAIDS; 1996.

8. Moraes JC, Seabra NSS, Eluf Neto J. São Paulo. In A Epidemia de AIDS no Brasil: Situação e Tendências [The AIDS epidemic in Brazil: current situation and trends]. Edited by Coordenação Nacional de DST e AIDS [National STD/AIDS Programme]. Brasília: Ministério da Saúde [Ministry of Health, Brazil]; 1997:145-179.

9. Barbieri D, Santos NJS, Guibo IA, Jamal LF, Caminada S, Domingues CSB. Investigation of cases and deaths by AIDS from 
death certificates. XIIth International Conference on AIDS. Geneva, June 1998 [abstract 43458].

10. Fowler MG, Melnick SL, Mathieson BJ. Women and HIV epidemiology and global overview. Obstet Gynecol Clin North Am 1997, 24:705-729.

11. Palella FJ, Delaney KM, Moorman AC, et al. Declining morbidity and mortality among patients with advanced human immunodeficiency virus infection. N Engl J Med 1998, 338:853-860.

12. Santos B, Beck EJ, Peixoto MF. Survival and medical intervention in southern Brazilian AIDS patients. Int J STD AIDS 1994, 5:279-283.

13. Santoro-Lopes G, Harrison LH, Moulton LH, et al. Gender and survival after AIDS in Rio de Janeiro, Brazil. J Acquir Immune Defic Syndr Hum Retrovirol 1998, 19:403-407.

14. Lemp GF, Hirozawa AM, Cohen JB, Derish PA, McKinney KC, Hernandez SR. Survival for women and men with AIDS. I Infect Dis 1992, 166:74-79.

15. Barbosa RM, Villela W. A trajetória feminina da AIDS. In:
Quebrando o Silêncio: Mulheres e AIDS no Brasil [Breaking the Silence: women and AIDS in Brazil]. Edited by Parker R, Galvão J. Rio de Janeiro: Relume-Dumará: ABIA:IMS/UERJ; 1996:17-32.

16. Santos N. A AIDS entre mulheres no Estado de São Paulo. Quebrando o Silêncio: Mulheres e AIDS no Brasil. Edited by Parker R, Galvão J. Rio de Janeiro: Relume-Dumará: ABIA: IMS/ UERJ; 1996:33-59.

17. Giffin K, Lowndes CM. Gender, sexuality, and the prevention of sexually transmissible diseases: a Brazilian study of clinical practice. Soc Sci Med 1999, 48:283-292.

18. Heath KV, Frank O, Montaner JSG, O'Shaughnessy MV, Schechter MT, Hogg RS. Human immunodeficiency virus (HIV)/ acquired immunodeficiency syndrome (AIDS) mortality in industrialised nations, 1987-1991. Int J Epidemiol 1998, 27:685-690.

19. UNAIDS/WHO. Report on the global HIV/AIDS epidemic, June 1998. Geneva: UNAIDS/WHO; 1998. 